\title{
Primeiras Impressões: Produção e Circulação de Romances no Início do Século XIX ${ }^{*}$ \\ First impressions: production and dissemination of novels at the beginning of the 19th century
}

\author{
Simone Cristina Mendonça de Souza**
}

A América portuguesa esteve por três séculos proibida de desenvolver empreendimentos tipográficos. Perseguidos com rigor por instituições de censura da Metrópole, os luso-brasileiros que se arriscassem a imprimir quaisquer obras poderiam ser deportados, juntamente com seus equipamentos de trabalho. Assim ocorreu com Antonio Isidoro da Fonseca, que imprimiu, em 1747, a inocente Relação da entrada que fez o excellentissimo, e reverendíssimo senhor D. F. Antonio do Desterro Malheyro bispo do Rio de Janeiro. Após ser descoberto, no mesmo ano dessa impressão, Antonio Isidoro teve seu material apreendido e remetido para Portugal. (HALLEWELL, 1985, p. 15-17).

Somente em 1808, quando da chegada de D. João VI, foi inaugurada a primeira casa impressora a funcionar legalmente, a Impressão Régia do Rio de Janeiro, que manteve a exclusividade de imprimir na Corte até 1821. Antes de 1808 , os leitores luso-brasileiros precisavam recorrer à importação de livros, submetendo-se a todo um processo de censura para conseguirem uma autorização para aquisição e transporte dos mesmos. ${ }^{1}$

do Estado de São Paulo / Fapesp.

O presente trabalho foi realizado com o apoio da Fundação de Amparo à pesquisa Unicamp.

*. Doutoranda em Teoria e História Literária da Universidade Estadual de Campinas/

1 Em 1768, houve a instituição da Real Mesa Censória, pelo Marquês de Pombal, a fim de unificar e laicizar a censura até então de responsabilidade do Santo Ofício, do Ordinário e do Desembargo do Paço. D. Maria I, em 1787, determinou a constituição da Real Mesa da Comissão Geral para o Exame e a Censura dos Livros, que foi extinta em 1794, quando as atribuições da Real Mesa passaram para o Santo Ofício e o Desembargo do Paço. Em 1808, quando da transferência da Corte para o Brasil, foi determinada a instituição da Mesa do Desembargo do Paço no Rio de Janeiro. Em Portugal, o Santo Ofício se manteve até 1821, quando foi extinto. A Secretaria da Censura do Desembargo do Paço de Lisboa, responsável a partir de então, cuidou da questão da censura, inclusive para o Brasil, até 1826, ano em que Portugal reconheceu a independência da colônia. 
A partir da fundação da Impressão Régia, num contexto de inúmeras providências práticas a fim de assentar a máquina administrativa monárquica que se mudara para a colônia, é que foi possível imprimir livros, folhetos, mapas e documentos no Brasil. No entanto, isso não interrompeu os pedidos de importação, ${ }^{2}$ que continuaram a ser requeridos junto aos órgãos da censura, impulsionados ainda mais pela abertura dos portos, também ocorrida em 1808.

Entre as providências administrativas tomadas, D. João VI ordenou que fossem abertos espaços para o desenvolvimento da cultura, para discussões políticas e para a divulgação das letras e das artes, como a Impressão Régia, em 1808; o Real Arquivo Militar, em 1808; a Biblioteca Pública, em 1810 e o Real Teatro São João, em 1813 (COSTA, 2002, p. 210-215).

Ressaltamos que o decreto de inauguração da Impressão Régia permitia que quaisquer obras fossem publicadas na casa, desde que as mesmas obtivessem as licenças dos censores régios e que fossem pagos os valores estipulados para a impressão. Poucos meses após a inauguração da casa impressora, foram publicados os números do primeiro periódico impresso na colônia, a Gazeta do Rio de Janeiro (1808-1821), ${ }^{3}$ onde figuravam os anúncios de mercadores que, entre os mais diversos produtos, ofereciam tratados técnicos, textos militares, gramáticas, dicionários, obras científicas, peças de teatro e novelas.

Apesar da censura vigente, textos de belas letras também alcançaram seu espaço nos prelos da Impressão Régia do Rio de Janeiro e merecem ser comentados. A maioria deles, sem dúvida, é formada por poemas encomiásticos, em homenagem aos nobres que habitavam o Rio de Janeiro da época, sobretudo à família Real. Também os textos de teatro encontraram prelos disponíveis na Impressão Régia, tanto antes quanto depois da inauguração do Real Teatro São João, em 1813.

Além de documentos e sonetos de lisonja, a casa publicou livros de prosa de ficção de conteúdos e formatos heterogêneos. De acordo com os levantamentos feitos pelos pesquisadores Alfredo do Valle Cabral, em seus Annaes da Imprensa Nacional do Rio de Janeiro 1808 a 1822, Ana Maria de Almeida Camargo e Rubens Borba de Moraes, em Bibliografia da Impressão Régia do Rio de Janeiro, 32 títulos podem ser considerados como publicações da casa em prosa de ficção.

2 Sobre importação e circulação de livros em prosa de ficção no período, consultar: ABREU, Márcia Azevedo de. Os caminhos dos livros. Campinas: Mercado de Letras, Associação de Leitura do Brasil (ALB); São Paulo: Fapesp, 2003.

3 A partir de junho de 1808 foi impresso, em Londres, o periódico Correio Brazilienze, ou, Armazém Literário, redigido por Hipólito José da Costa (1774-1823), luso-brasileiro formado em Coimbra, enviado à Inglaterra, inicialmente a serviço da Impressão Régia de Lisboa e exilado em Londres por suspeitas de envolvimento com a maçonaria. O Correio Braziliense chegava ao Brasil pela importação, apesar das tentativas do governo joanino de deter sua circulação em território português. (DINES, Alberto. Um patriarca e seu modelo. In: COSTA, Hipólito José da. Correio Braziliense, ou Armazén Literário. Hipólito José da Costa. São Paulo: Imprensa Oficial do Estado; Brasília: Correio Braziliense, 2002). 
Com o objetivo de encontrar essas publicações, foram realizadas pesquisas junto a instituições brasileiras e portuguesas, ${ }^{4} \mathrm{e}$, até o momento, encontrados 10 romances efetivamente editados na Impressão Régia do Rio de Janeiro, além de 14 dados à luz pela Impressão Régia de Lisboa ou por outras editoras portuguesas, em períodos próximos aos atribuídos à casa impressora oficial do Brasil colônia. Como não pudemos localizar todos os títulos, preferimos atribuir à Impressão Régia do Rio de Janeiro apenas as edições encontradas, cujas informações da folha de rosto podem isso confirmar. Os dados bibliográficos dos livros encontrados, bem como as poucas informações que dispomos sobre os não encontrados, foram sistematizados na tabela 1 a seguir, que também aponta a localização dos mesmos. ${ }^{5}$

Todas essas obras beletrísticas eram anunciadas no quadro de avisos da Gazeta do Rio de Janeiro e, mais tarde, nas seções de $O$ Patriota: jornal literário, político, mercantil (1813-1814) e do Diário do Rio de Janeiro (a partir de 1821). Ainda que consideremos a linguagem publicitária aplicada aos anúncios, observamos que estes prenunciavam a configuração de um mercado livreiro em nosso país e os primeiros indícios de uma crítica literária.

Também sahio á luz a Novella intitulada $A$ Choupana India, traduzida do Francez do celebre Abade St. Pierre. O nome do author basta para conceituar o merecimento da Obra, além da multiplicidade de Impressões, que se tem publicado em todos os idiomas. Vende-se na loja da Gazeta a 640 réis; aonde se acha o Diabo Coxo, 2 vol., por $1 \$ 600$ réis _ Novella que igualmente tem encontrado geral aceitação. (Gazeta do Rio de Janeiro, 10/07/1811).

Os títulos de livros de prosa de ficção, anunciados como "novelas", ${ }^{6}$ nos revelam um conjunto heterogêneo de textos em diversas formas

4 Biblioteca Nacional do Rio de Janeiro, Biblioteca da Academia Brasileira de Letras, Biblioteca do Instituto Histórico Geográfico, Acervo Pessoal do Bibliófilo José E. Mindlin, Acervo do IEB/USP, Biblioteca Nacional de Lisboa e Biblioteca da Universidade Católica João Paulo II (em Lisboa). [nas instituições portuguesas, as pesquisas foram realizadas por Márcia Abreu].

5 Tentamos reunir o maior número de dados possíveis, mas nem sempre a indicação pode ser citada de forma completa. Quando não havia nenhum dado disponível, as células foram deixadas em branco. O mesmo ocorreu nos casos em que não havia o anúncio dos jornais ou quando nenhum exemplar foi localizado. Há dúvida quanto à classificação dos seguintes títulos: Cartas familiares, amorozas e ternas de huma amante a seu apaixonado; A Farofia, ou loucura dos casamentos por huma Ratazana e Perigos Descobertos.

6 Optaremos por denominar os textos de prosa de ficção como romances, uma vez que, na época em que esses textos foram publicados pela Impressão Régia, não havia ainda uma classificação clara para os diferentes gêneros literários, considerados, de maneira geral, como de belas-letras. Algumas das publicações em prosa de ficção da Impressão Régia foram anunciadas como "novellas", outras como "conto moral", outras apenas pelo título. 
SOUZA, S. C. M. de. Primeiras impressões: produção e circulação de romances...

Tabela 1: Resumo dos dados bibliográficos sobre os romances apresentados:

\begin{tabular}{|c|c|c|c|c|c|c|}
\hline Título ${ }^{7}$ & Autor ${ }^{8}$ & Tradutor $^{9}$ & $\begin{array}{c}\text { Edições } \\
\text { portuguesas } \\
\text { encontradas }\end{array}$ & $\begin{array}{c}\text { Edições } \\
\text { luso- } \\
\text { brasileiras } \\
\text { encontradas }\end{array}$ & $\begin{array}{l}\text { 1q anúncio } \\
\text { no Rio de } \\
\text { Janeiro }^{10}\end{array}$ & Localização \\
\hline $\begin{array}{l}\text { A amante } \\
\text { militar: } \\
\text { novella }\end{array}$ & & & $\begin{array}{l}\text { Lisboa: } \\
\text { Impressão } \\
\text { Régia: } 1816\end{array}$ & & $\begin{array}{l}\text { Gazeta do } \\
\text { Rio de } \\
\text { Janeiro: } 06 / \\
06 / 1816 \\
\text { (loja da } \\
\text { Gazeta) }\end{array}$ & $\begin{array}{l}\text { Biblioteca } \\
\text { Nacional de } \\
\text { Lisboa. } \\
\text { Cota: L } \\
6615 / / 5 \mathrm{P} \\
\text { L46033 P }\end{array}$ \\
\hline $\begin{array}{l}\text { (O crime } \\
\text { mais } \\
\text { horroroso } \\
\text { ou) o amigo } \\
\text { traidor }\end{array}$ & $\begin{array}{l}\text { Alain-René } \\
\text { Lesage } \\
\text { (Sarzeau, } \\
1668- \\
\text { Boulogne- } \\
\text { sur-Mer, } \\
1747 \text { ) }\end{array}$ & $\begin{array}{l}\text { A.J.B.- } \\
\text { Antonio } \\
\text { Inocencio } \\
\text { Barbuda } \\
\\
\text { Ou } \\
\text { Antonio } \\
\text { José } \\
\text { Baptista, f. } \\
17 . . \\
\text { (porbase) }\end{array}$ & $\begin{array}{l}\text { Lisboa: } \\
\text { Impressão } \\
\text { Régia, } 1815 \\
\text { Lisboa: } \\
\text { Impressão } \\
\text { Régia, } 1819\end{array}$ & & $\begin{array}{l}\text { Gazeta do } \\
\text { Rio de } \\
\text { Janeiro: 06/ } \\
06 / 1816 \\
\text { (loja da } \\
\text { Gazeta) }\end{array}$ & $\begin{array}{l}\text { Biblioteca } \\
\text { Nacional de } \\
\text { Lisboa. } \\
\text { Cota: L } \\
6597 \text { 2P } \\
\text { (ed. 1815). } \\
\text { Biblioteca } \\
\text { Nacional de } \\
\text { Lisboa. } \\
\text { Cota: L } \\
11235 / / 7 \mathrm{P} \\
\text { (ed. 1819). }\end{array}$ \\
\hline $\begin{array}{l}\text { O amor } \\
\text { offendido e } \\
\text { vingado }\end{array}$ & Werbrocke & & $\begin{array}{l}\text { Lisboa: } \\
\text { Impressão } \\
\text { Régia, } 1818 \\
\text { Lisboa: Off. } \\
\text { Antonio } \\
\text { Gomes, } \\
1794\end{array}$ & & $\begin{array}{l}\text { Gazeta do } \\
\text { Rio de } \\
\text { Janeiro: } 24 / \\
01 / 1816 \\
\text { (loja da } \\
\text { Gazeta) }\end{array}$ & $\begin{array}{l}\text { Biblioteca } \\
\text { Nacional de } \\
\text { Lisboa. } \\
\text { Cota: L } \\
66027 \mathrm{P} \\
\text { (ed. 1818). } \\
\text { Biblioteca } \\
\text { Nacional de } \\
\text { Lisboa. } \\
\text { Cota: F } \\
7791 \\
\text { (ed. 1794) }\end{array}$ \\
\hline $\begin{array}{l}\text { Aventuras } \\
\text { galantes de } \\
\text { dois } \\
\text { fidalgos } \\
\text { estudantes } \\
\text { ou a } \\
\text { historia } \\
\text { admirável } \\
\text { da famosa } \\
\text { Cornelia de } \\
\text { Bolonha }\end{array}$ & & & $\begin{array}{l}\text { Lisboa: } \\
\text { Impressão de } \\
\text { Alcobia, } \\
1816\end{array}$ & & $\begin{array}{l}\text { Gazeta do } \\
\text { Rio de } \\
\text { Janeiro: 09/ } \\
12 / 1818 \\
\text { (loja da } \\
\text { Gazeta) }\end{array}$ & $\begin{array}{l}\text { Biblioteca } \\
\text { Nacional de } \\
\text { Lisboa. } \\
\text { Cota: } 65971 \\
\text { P (ed. 1816). }\end{array}$ \\
\hline $\begin{array}{l}\text { Aventuras } \\
\text { pasmosas do } \\
\text { celebre } \\
\text { barão de } \\
\text { Munkausen. } \\
\text { Que contem } \\
\text { hum resumo } \\
\text { de viagens, } \\
\text { campanhas, } \\
\text { jornadas e } \\
\text { aventuras } \\
\text { extraordiná- } \\
\text { rias } \\
\text { igualmente a } \\
\text { descripção } \\
\text { de huma } \\
\text { viagem á } \\
\text { Lua e } \\
\text { Canicula }\end{array}$ & $\begin{array}{l}\text { Erich Rudolf } \\
\text { Raspe } \\
\text { (Hanovre, } \\
1737- \\
\text { Mukross/ } \\
\text { Irlande, } \\
1794 \text { ) }\end{array}$ & $\begin{array}{l}\text { André } \\
\text { Jacob }^{12}\end{array}$ & $\begin{array}{l}\text { Lisboa: } \\
\text { Typographia } \\
\text { Rollandiana, } \\
1835\end{array}$ & $\begin{array}{l}\text { Rio de } \\
\text { Janeiro: } \\
\text { Impressão } \\
\text { Régia, } 1814 .\end{array}$ & $\begin{array}{l}\text { Gazeta do } \\
\text { Rio de } \\
\text { Janeiro: 17/ } \\
\text { 12/1814 } \\
\text { (Manoel } \\
\text { Mandilo) }\end{array}$ & $\begin{array}{l}\text { Real } \\
\text { Gabinete } \\
\text { Português } \\
\text { de Leitura. } \\
\text { Cota: } \\
29269 \text {, } \\
\text { estante 29. } \\
\text { (ed. 1835). } \\
\text { Acervo } \\
\text { Pessoal } \\
\text { José E. } \\
\text { Mindlin. } \\
\text { Cota: JM } \\
\text { S4ee } \\
\text { (edição } \\
\text { 1814). }\end{array}$ \\
\hline A boa mãi & $\begin{array}{l}\text { Jean } \\
\text { François } \\
\text { Marmontel } \\
\text { (Bort-les- } \\
\text { Orgues, } \\
1723- \\
\text { Abouville/ } \\
\text { Eure, 1799) }\end{array}$ & & $\begin{array}{l}\text { Lisboa: } \\
\text { Impressão } \\
\text { Régia, } 1817\end{array}$ & & $\begin{array}{l}\text { Gazeta do } \\
\text { Rio de } \\
\text { Janeiro: } 24 / \\
01 / 1816 \\
\text { (loja da } \\
\text { Gazeta) }\end{array}$ & $\begin{array}{l}\text { Biblioteca } \\
\text { Nacional de } \\
\text { Lisboa. } \\
\text { Cota: } \\
\text { L6602 P } \\
\text { (ed. 1817) }\end{array}$ \\
\hline $\begin{array}{l}O \text { bom } \\
\text { marido }\end{array}$ & $\begin{array}{l}\text { Jean } \\
\text { François } \\
\text { Marmontel } \\
\text { (Bort-les- } \\
\text { Orgues, } \\
1723- \\
\text { Abouville/ } \\
\text { Eure, 1799) }\end{array}$ & & $\begin{array}{l}\text { Lisboa: } \\
\text { Impressão } \\
\text { Régia, } 1817\end{array}$ & & $\begin{array}{l}\text { Gazeta do } \\
\text { Rio de } \\
\text { Janeiro: } 24 / \\
01 / 1816 \\
\text { (loja da } \\
\text { Gazeta) }\end{array}$ & $\begin{array}{l}\text { Biblioteca } \\
\text { Nacional de } \\
\text { Lisboa. } \\
\text { Cota: } \\
\text { L6602 } 3 \text { P } \\
\text { (ed. 1817) }\end{array}$ \\
\hline
\end{tabular}


SOUZA, S. C. M. de. Primeiras impressões: produção e circulação de romances...

\begin{tabular}{|c|c|c|c|c|c|c|}
\hline Título & Autor & Tradutor & $\begin{array}{c}\text { Edições } \\
\text { portuguesas } \\
\text { encontradas }\end{array}$ & $\begin{array}{c}\text { Edições } \\
\text { luso- } \\
\text { brasileiras } \\
\text { encontradas }\end{array}$ & $\begin{array}{c}\text { 1q anúncio } \\
\text { no Rio de } \\
\text { Janeiro }\end{array}$ & Localização \\
\hline $\begin{array}{l}\text { (Novella, ou } \\
\text { conto } \\
\text { intutulado) } \\
\text { A cadelinha }\end{array}$ & $\begin{array}{l}\text { Antonio } \\
\text { Manuel } \\
\text { Policarpo da } \\
\text { Silva }\end{array}$ & & $\begin{array}{l}\text { Lisboa: } \mathrm{Na} \\
\text { Nova } \\
\text { Impressão da } \\
\text { Viuva Neves } \\
\text { e Filhos, } \\
1816\end{array}$ & & $\begin{array}{l}\text { Gazeta do } \\
\text { Rio de } \\
\text { Janeiro: 06/ } \\
06 / 1816 \\
\text { (loja da } \\
\text { Gazeta) }\end{array}$ & $\begin{array}{l}\text { Biblioteca } \\
\text { Nacional de } \\
\text { Lisboa. } \\
\text { Cota: } \\
\text { L6616 } 7 \text { P } \\
\text { (ed. 1816) }\end{array}$ \\
\hline $\begin{array}{l}\text { Carta de } \\
\text { Heloaze a } \\
\text { Abailardo }\end{array}$ & $\begin{array}{l}\text { Alexander } \\
\text { Pope [?] } \\
\text { (1688-1744) }\end{array}$ & $\begin{array}{l}\text { D. } \\
\text { Marianna } \\
\text { Alcoforado } \\
{[?]} \\
(1640- \\
1723)\end{array}$ & & $\begin{array}{l}\text { Rio de } \\
\text { Janeiro: } \\
\text { Impressão } \\
\text { Régia. }\end{array}$ & $\begin{array}{l}\text { Gazeta do } \\
\text { Rio de } \\
\text { Janeiro: 02/ } \\
12 / 1812 \\
\text { (loja da } \\
\text { Gazeta) }\end{array}$ & $\begin{array}{l}\text { Biblioteca } \\
\text { Nacional } \\
\text { do Rio de } \\
\text { Janeiro. } \\
\text { Cota: } 37,5, \\
23 \\
\text { (ed. Rio de } \\
\text { Janeiro) }\end{array}$ \\
\hline $\begin{array}{l}\text { Carta } \\
\text { escrita pela } \\
\text { senhora de } \\
\text { sen, rezidente } \\
\text { em } \\
\text { Constantinopla } \\
\text { a huma sua } \\
\text { amiga, em } \\
\text { que trata } \\
\text { das } \\
\text { mulheres } \\
\text { turcas, do } \\
\text { seu, odo de } \\
\text { viver, } \\
\text { divertimen- } \\
\text { tos, vestidos, } \\
\text { maneira de } \\
\text { tratar os } \\
\text { maridos, \&c. }\end{array}$ & $\begin{array}{l}\text { Mary } \\
\text { Wortley } \\
\text { Montagu } \\
(1689-1762)\end{array}$ & & & & $\begin{array}{l}\text { Gazeta do } \\
\text { Rio de } \\
\text { Janeiro: 22/ } \\
12 / 1819 \\
\text { (Manoel } \\
\text { Joaquim da } \\
\text { Silva } \\
\text { Porto) }\end{array}$ & \\
\hline $\begin{array}{l}\text { Cartas } \\
\text { americanas }\end{array}$ & $\begin{array}{l}\text { Theodoro } \\
\text { José } \\
\text { Biancardi } \\
\text { (Lisboa, } \\
1777-\text { Rio } \\
\text { de Janeiro } \\
\text { ??) }\end{array}$ & & $\begin{array}{l}\text { Lisboa: } \\
\text { Impressão } \\
\text { Régia, } 1809 \\
\text { Lisboa: } \\
\text { Impressão } \\
\text { de Alcobia, } \\
1820\end{array}$ & & $\begin{array}{l}\text { Gazeta do } \\
\text { Rio de } \\
\text { Janeiro: 30/ } \\
06 / 1810 \\
\text { (Manoel } \\
\text { Pereira de } \\
\text { Mesquita) }\end{array}$ & $\begin{array}{l}\text { Acervo } \\
\text { Pessoaal } \\
\text { José E. } \\
\text { Mindlin. } \\
\text { Cota: P 4b } \\
\text { (ed. 1809). } \\
\text { Biblioteca } \\
\text { Nacional de } \\
\text { Lisboa. } \\
\text { Cota: L } \\
\text { 8703 P (ed. } \\
\text { 1809). } \\
\text { Biblioteca } \\
\text { Nacional } \\
\text { do Rio de } \\
\text { Janeiro. } \\
\text { Cota: 79, 1, } \\
\text { 20 (ed. } \\
\text { 1820). }\end{array}$ \\
\hline $\begin{array}{l}\text { Cartas } \\
\text { familiares, } \\
\text { amorozas e } \\
\text { ternas de } \\
\text { huma } \\
\text { amante a seu } \\
\text { apaixonado }\end{array}$ & & & & & $\begin{array}{l}\text { Diário do } \\
\text { Rio de } \\
\text { Janeiro: 12/ } \\
12 / 1822 \\
\text { (Paulo } \\
\text { Martin } \\
\text { Filho) }\end{array}$ & \\
\hline $\begin{array}{l}\text { Cartas de } \\
\text { huma } \\
\text { peruviana }\end{array}$ & $\begin{array}{l}\text { Françoise } \\
\text { d'Issembourg } \\
\text { d'Happoncourt } \\
\text { de Graffigny } \\
\text { (Nancy, 1695 } \\
\text { - Paris, } \\
1758 \text { ) }\end{array}$ & & $\begin{array}{l}\text { Lisboa: } \\
\text { Officina } \\
\text { Simão } \\
\text { Thaddeo } \\
\text { Ferreira, } \\
1802\end{array}$ & & $\begin{array}{l}\text { Gazeta do } \\
\text { Rio de } \\
\text { Janeiro: 02/ } \\
12 / 1812 \\
\text { (Manoel } \\
\text { Joaquim } \\
\text { Alves } \\
\text { Porto) }\end{array}$ & $\begin{array}{l}\text { Biblioteca } \\
\text { da } \\
\text { Universida- } \\
\text { de Católica } \\
\text { João Paulo } \\
\text { II/Lisboa. } \\
\text { Cota: LE } \\
307 \text { (ed. } \\
1802)\end{array}$ \\
\hline $\begin{array}{l}O \text { castigo da } \\
\text { prostituição }\end{array}$ & $\begin{array}{l}\text { Edward } \\
\text { Young [?] } \\
(1683-1765)\end{array}$ & & $\begin{array}{l}\text { Lisboa: } \\
\text { Impressão } \\
\text { Régia, } 1818\end{array}$ & $\begin{array}{l}\text { Rio de } \\
\text { Janeiro: } \\
\text { Impressão } \\
\text { Régia, } 1815 .\end{array}$ & $\begin{array}{l}\text { Gazeta do } \\
\text { Rio de } \\
\text { Janeiro: } 24 / \\
01 / 1816 \\
\text { (loja da } \\
\text { Gazeta) }\end{array}$ & $\begin{array}{l}\text { Biblioteca } \\
\text { Nacional } \\
\text { do Rio de } \\
\text { Janeiro. } \\
\text { Cota: } 37, \\
\text { 10, } 9 \text { (ed. } \\
1815 \text { ). } \\
\text { Biblioteca } \\
\text { Nacional de } \\
\text { Lisboa. } \\
\text { Cota: L } \\
\text { 6602 P (ed. } \\
\text { 1818). }\end{array}$ \\
\hline
\end{tabular}


SOUZA, S. C. M. de. Primeiras impressões: produção e circulação de romances...

\begin{tabular}{|c|c|c|c|c|c|c|}
\hline Título & Autor & Tradutor & $\begin{array}{c}\text { Edições } \\
\text { portuguesas } \\
\text { encontradas }\end{array}$ & $\begin{array}{c}\text { Edições } \\
\text { luso- } \\
\text { brasileiras } \\
\text { encontradas }\end{array}$ & $\begin{array}{l}\text { 1q anúncio } \\
\text { no Rio de } \\
\text { Janeiro }\end{array}$ & Localização \\
\hline $\begin{array}{l}\text { A Choupana } \\
\text { India }\end{array}$ & $\begin{array}{l}\text { Jacques- } \\
\text { Henri } \\
\text { Bernardin de } \\
\text { Saint Pierre } \\
\text { (le Havre, } \\
1737- \\
\text { Erangny-sur- } \\
\text { Oise, 1814) }\end{array}$ & & $\begin{array}{l}\text { Lisboa: } \\
\text { Typografia } \\
\text { Rollandiana, } \\
1806\end{array}$ & & $\begin{array}{l}\text { Gazeta do } \\
\text { Rio de } \\
\text { Janeiro: } 10 / \\
07 / 1811 \\
\text { (loja da } \\
\text { Gazeta) }\end{array}$ & $\begin{array}{l}\text { Biblioteca } \\
\text { Nacional de } \\
\text { Lisboa. } \\
\text { Cota: L } 6686 \\
\text { P (ed. 1806) }\end{array}$ \\
\hline $\begin{array}{l}\text { O combate } \\
\text { das paixões }\end{array}$ & & D. L. & $\begin{array}{l}\text { Lisboa: } \\
\text { Impressão } \\
\text { Régia, } 1816\end{array}$ & & $\begin{array}{l}\text { Gazeta do } \\
\text { Rio de } \\
\text { Janeiro: } 06 / \\
06 / 1816 \\
\text { (loja da } \\
\text { Gazeta) } \\
\end{array}$ & $\begin{array}{l}\text { Biblioteca } \\
\text { Nacional de } \\
\text { Lisboa. } \\
\text { Cota: } 66161 \\
\text { P (ed. } 1816 \text { ) }\end{array}$ \\
\hline $\begin{array}{l}\text { O diabo } \\
\text { Coxo }\end{array}$ & $\begin{array}{l}\text { Alain-René } \\
\text { Lesage } \\
\text { (Sarzeau, } \\
1668- \\
\text { Boulogne- } \\
\text { sur-Mer, } \\
1747 \text { ) }\end{array}$ & $\begin{array}{l}\text { Pedro Freire } \\
\text { de Oliveira } \\
(1758-1814)\end{array}$ & & $\begin{array}{l}\text { Rio de } \\
\text { Janeiro: } \\
\text { Impressão } \\
\text { Régia, } 1810\end{array}$ & $\begin{array}{l}\text { Gazeta do } \\
\text { Rio de } \\
\text { Janeiro: 26/ } \\
01 / 1811 \\
\text { (Manoel } \\
\text { Pereira de } \\
\text { Mesquita) }\end{array}$ & $\begin{array}{l}\text { Acervo } \\
\text { Pessoal } \\
\text { José E. } \\
\text { Mindlin. } \\
\text { Cota: RBM } \\
\text { 8e (ed. } \\
1810) \text {. } \\
\end{array}$ \\
\hline $\begin{array}{l}\text { As duas } \\
\text { desafortuna- } \\
\text { das }\end{array}$ & $\begin{array}{l}\text { Jean } \\
\text { François } \\
\text { Marmontel } \\
\text { (Bort-les- } \\
\text { Orgues, } \\
1723- \\
\text { Abouville/ } \\
\text { Eure, 1799) }\end{array}$ & & $\begin{array}{l}\text { Lisboa: } \\
\text { Impressão } \\
\text { Régia, } 1818\end{array}$ & $\begin{array}{l}\text { Rio de } \\
\text { Janeiro: } \\
\text { Impressão } \\
\text { Régia, } 1815\end{array}$ & $\begin{array}{l}\text { Gazeta do } \\
\text { Rio de } \\
\text { Janeiro: } 24 / \\
01 / 1816 \\
\text { (loja da } \\
\text { Gazeta) }\end{array}$ & $\begin{array}{l}\text { Biblioteca } \\
\text { Nacional de } \\
\text { Lisboa. } \\
\text { Cota: L } \\
6602 \text { P } \\
\text { (ed. 1815). } \\
\text { Biblioteca } \\
\text { Nacional } \\
\text { do Rio de } \\
\text { Janeiro. } \\
\text { Cota: } 37, \\
10,8 \text { (ed. } \\
\text { 1815 - Rio } \\
\text { de Janeiro). }\end{array}$ \\
\hline $\begin{array}{l}\text { A } \\
\text { Farofia,das } \\
\text { farofias, ou } \\
\text { a loucura } \\
\text { dos } \\
\text { casamentos } \\
\text { por hum } \\
\text { ratazana } \\
\text { velho, a que } \\
\text { tem ladrado } \\
\text { muito gozo }\end{array}$ & & & $\begin{array}{l}\text { Lisboa: } \\
\text { Typografia } \\
\text { Numesiana, } \\
1790 .\end{array}$ & & $\begin{array}{l}\text { Diário do } \\
\text { Rio de } \\
\text { Janeiro: } 04 / \\
06 / 1822\end{array}$ & $\begin{array}{l}\text { Biblioteca } \\
\text { Nacional de } \\
\text { Lisboa. } \\
\text { Cota: L } \\
69513 \text { P }\end{array}$ \\
\hline $\begin{array}{l}\text { A filósofa } \\
\text { por amor ou } \\
\text { cartas de } \\
\text { dois } \\
\text { amantes } \\
\text { apaixonados } \\
\text { e virtuosos }\end{array}$ & $\begin{array}{l}\text { Rétif de la } \\
\text { Bretonne } \\
(1734-1806)\end{array}$ & $\begin{array}{l}\text { Luís Caetano } \\
\text { de Campos } \\
(1750- \\
1820)\end{array}$ & & $\begin{array}{l}\text { Rio de } \\
\text { Janeiro: } \\
\text { Impressão } \\
\text { Régia, } 1811\end{array}$ & $\begin{array}{l}\text { Gazeta do } \\
\text { Rio de } \\
\text { Janeiro: 25/ } \\
\text { 03/1812 } \\
\text { (Paulo } \\
\text { Martin } \\
\text { Filho) }\end{array}$ & $\begin{array}{l}\text { Biblioteca } \\
\text { da } \\
\text { Universida- } \\
\text { de Católica } \\
\text { João Paulo } \\
\text { II/Lisboa. } \\
\text { Cota: CP-LE } \\
1894 \text { (ed. } \\
1811 \text { ) }\end{array}$ \\
\hline $\begin{array}{l}\text { História de } \\
\text { dois } \\
\text { amantes ou } \\
\text { o templo de } \\
\text { Jatab }\end{array}$ & $\begin{array}{l}\text { Henri } \\
\text { François de } \\
\text { la Salle [?] } \\
\text { Ou } \\
\text { Claude } \\
\text { Godard } \\
\text { d'Aucour } \\
\text { (1716- } \\
1795)\end{array}$ & $\begin{array}{l}\text { José [João?] } \\
\text { Pedro de } \\
\text { Souza } \\
\text { Azevedo } \\
(? ? ? ?-1812)\end{array}$ & & $\begin{array}{l}\text { Rio de } \\
\text { Janeiro, } \\
\text { Impressão } \\
\text { Régia, } 1811\end{array}$ & $\begin{array}{l}\text { Gazeta do } \\
\text { Rio de } \\
\text { Janeiro: 20/ } \\
11 / 1811 \\
\text { (loja da } \\
\text { Gazeta) }\end{array}$ & $\begin{array}{l}\text { Acervo } \\
\text { Pessoal } \\
\text { José E. } \\
\text { Mindlin. } \\
\text { Cota: RBM } \\
\text { 8d (ed. } \\
1811) \text {. } \\
\text { Acervo } \\
\text { IEB. Cota: } \\
\text { L^19^334 } \\
\text { (ed. 1811). } \\
\text { British } \\
\text { Library. } \\
\text { Shelfmark: } \\
8042 \text {. bb. } \\
\text { 26. (8) 4 } \\
\text { (ed. 1811) }\end{array}$ \\
\hline
\end{tabular}


SOUZA, S. C. M. de. Primeiras impressões: produção e circulação de romances...

\begin{tabular}{|c|c|c|c|c|c|c|}
\hline Título & Autor & Tradutor & $\begin{array}{c}\text { Edições } \\
\text { portuguesas } \\
\text { encontradas }\end{array}$ & $\begin{array}{c}\text { Edições } \\
\text { luso- } \\
\text { brasileiras } \\
\text { encontradas }\end{array}$ & $\begin{array}{l}\text { 1q anúncio } \\
\text { no Rio de } \\
\text { Janeiro }\end{array}$ & Localização \\
\hline $\begin{array}{l}\text { Historia da } \\
\text { donzella } \\
\text { Theodora, } \\
\text { em que se } \\
\text { trata da sua } \\
\text { grande } \\
\text { formosura, e } \\
\text { sabedoria. }\end{array}$ & $\begin{array}{l}\text { Juana Milian } \\
\text { [?] }\end{array}$ & $\begin{array}{l}\text { Carlos } \\
\text { Ferreira } \\
\text { Lisbonense }\end{array}$ & & $\begin{array}{l}\text { Rio de } \\
\text { Janeiro, } \\
\text { Impressão } \\
\text { Régia, } 1815\end{array}$ & & $\begin{array}{l}\text { Biblioteca } \\
\text { Nacional } \\
\text { do Rio de } \\
\text { Janeiro. } \\
\text { Cota: } 37, \\
\text { 10, 3b (ed. } \\
1815 \text { ) } \\
\text { Biblioteca } \\
\text { Nacional de } \\
\text { Lisboa. } \\
\text { Cota: L } \\
\text { 4980 V (ed. } \\
1815)\end{array}$ \\
\hline $\begin{array}{l}\text { Historia } \\
\text { verdadeira } \\
\text { da princeza } \\
\text { Magalona, } \\
\text { filha delrei } \\
\text { de Nápoles, } \\
\text { e do nobre e } \\
\text { valeroso } \\
\text { cavalleiro } \\
\text { Pierre Pedro } \\
\text { de Proença, } \\
\text { e dos muitos } \\
\text { trabalhos, e } \\
\text { diversidades } \\
\text { que } \\
\text { passarão, } \\
\text { sendo } \\
\text { sempre } \\
\text { constantes } \\
\text { na fé, e } \\
\text { virtude; e } \\
\text { como depois } \\
\text { reinarão, e } \\
\text { acabarão a } \\
\text { sua vida } \\
\text { virtuosa- } \\
\text { mente no } \\
\text { serviço de } \\
\text { Deus }\end{array}$ & $\begin{array}{l}\text { Bernardo de } \\
\text { Treviers [?] }\end{array}$ & & $\begin{array}{l}\text { Lisboa: } \\
\text { Officina de } \\
\text { Simão } \\
\text { Thaddeo } \\
\text { Ferreira, } \\
1794\end{array}$ & & & $\begin{array}{l}\text { Biblioteca } \\
\text { Nacional de } \\
\text { Lisboa. } \\
\text { Cota: L } 4980 \\
10 \text { V (ed. } \\
1794 \text { ) }\end{array}$ \\
\hline $\begin{array}{l}\text { A infidelida- } \\
\text { de vingada }\end{array}$ & & & $\begin{array}{l}\text { Lisboa: } \\
\text { Impressão } \\
\text { Régia, } 1818\end{array}$ & & $\begin{array}{l}\text { Gazeta do } \\
\text { Rio de } \\
\text { Janeiro: } 24 / \\
01 / 1816 \\
\text { (loja da } \\
\text { Gazeta) }\end{array}$ & $\begin{array}{l}\text { Biblioteca } \\
\text { Nacional de } \\
\text { Lisboa. } \\
\text { Cota: L } 6602 \\
8 \text { P (ed. } \\
1818 \text { ) }\end{array}$ \\
\hline $\begin{array}{l}\text { Lausus e } \\
\text { Lydia: conto } \\
\text { historico }\end{array}$ & & & $\begin{array}{l}\text { Lisboa: } \\
\text { Officina de } \\
\text { Joaquim } \\
\text { Thomaz de A. } \\
\text { Bulhões, } \\
1815\end{array}$ & & $\begin{array}{l}\text { Gazeta do } \\
\text { Rio de } \\
\text { Janeiro: 06/ } \\
06 / 1816 \\
\text { (loja da } \\
\text { Gazeta) }\end{array}$ & $\begin{array}{l}\text { Biblioteca } \\
\text { Nacional de } \\
\text { Lisboa. } \\
\text { Cota: } 65974 \\
\text { P }\end{array}$ \\
\hline $\begin{array}{l}\text { Leitura para } \\
\text { os meninos, } \\
\text { contendo } \\
\text { huma } \\
\text { collecção de } \\
\text { Historias } \\
\text { Moraes } \\
\text { relativas } \\
\text { aos defeitos } \\
\text { ordinarios } \\
\text { ás idades } \\
\text { tenras, e } \\
\text { hum dialogo } \\
\text { sobre a } \\
\text { Geografia, } \\
\text { Chronologia, } \\
\text { Historia de } \\
\text { Portugal, e } \\
\text { Historia } \\
\text { Natural }\end{array}$ & $\begin{array}{l}\text { José } \\
\text { Saturnino da } \\
\text { Costa } \\
\text { Pereira } \\
\text { (Sacramento, } \\
1773 \text { - Rio } \\
\text { de Janeiro, } \\
1852 \text { ) }\end{array}$ & & & & $\begin{array}{l}\text { Gazeta do } \\
\text { Rio de } \\
\text { Janeiro: 10/ } \\
06 / 1818 \\
\text { (loja da } \\
\text { Gazeta e } \\
\text { Manoel } \\
\text { Joaquim da } \\
\text { Silva Porto) }\end{array}$ & \\
\hline$A$ má mãi & $\begin{array}{l}\text { Jean } \\
\text { François } \\
\text { Marmontel } \\
\text { (Bort-les- } \\
\text { Orgues, } \\
1723- \\
\text { Abouville/ } \\
\text { Eure, 1799) }\end{array}$ & & $\begin{array}{l}\text { Lisboa: } \\
\text { Impressão } \\
\text { Régia, } 1818\end{array}$ & & $\begin{array}{l}\text { Gazeta do } \\
\text { Rio de } \\
\text { Janeiro: } 24 / \\
01 / 1816\end{array}$ & $\begin{array}{l}\text { Biblioteca } \\
\text { Nacional de } \\
\text { Lisboa. } \\
\text { Cota: L } 6602 \\
4 \text { P (ed. } \\
1818 \text { ) }\end{array}$ \\
\hline
\end{tabular}


SOUZA, S. C. M. de. Primeiras impressões: produção e circulação de romances...

\begin{tabular}{|c|c|c|c|c|c|c|}
\hline Título & Autor & Tradutor & $\begin{array}{c}\text { Edições } \\
\text { portuguesas } \\
\text { encontradas }\end{array}$ & $\begin{array}{c}\text { Edições } \\
\text { luso- } \\
\text { brasileiras } \\
\text { encontradas }\end{array}$ & $\begin{array}{c}\text { 1q anúncio } \\
\text { no Rio de } \\
\text { Janeiro }\end{array}$ & Localização \\
\hline $\begin{array}{l}\text { Metusko ou } \\
\text { os Polacos }\end{array}$ & $\begin{array}{l}\text { Charles } \\
\text { Antoine } \\
\text { Guillaume } \\
\text { Pigault de } \\
\text { l'Epinoy } \\
\text { [Pigault } \\
\text { Lebrun] } \\
\text { (Calais, } \\
1753-- \\
\text { Saint-Cloud, } \\
1835 \text { ) }\end{array}$ & $\begin{array}{l}\text { Joaquim José } \\
\text { Pedro Lopes } \\
\text { (Lisboa, } \\
1778- \\
\text { Lisboa, } \\
1840 \text { ) }\end{array}$ & $\begin{array}{l}\text { Lisboa: } \\
\text { Impressão } \\
\text { Régia, } 1815\end{array}$ & & $\begin{array}{l}\text { Gazeta do } \\
\text { Rio de } \\
\text { Janeiro: } 06 / \\
06 / 1816 \\
\text { (loja da } \\
\text { Gazeta) }\end{array}$ & $\begin{array}{l}\text { Biblioteca } \\
\text { Nacional de } \\
\text { Lisboa. } \\
\text { Cota: L } 6597 \\
1 \text { P (ed. } \\
1815 \text { ) }\end{array}$ \\
\hline $\begin{array}{l}\text { Paulo e } \\
\text { Virginia } \\
\text { história } \\
\text { fundada em } \\
\text { factos }\end{array}$ & $\begin{array}{l}\text { Jacques- } \\
\text { Henri } \\
\text { Bernardin de } \\
\text { Saint Pierre } \\
\text { (le Havre, } \\
1737- \\
\text { Erangny-sur- } \\
\text { Oise, 1814) }\end{array}$ & & $\begin{array}{l}\text { Lisboa: } \\
\text { Typografia } \\
\text { Rollandiana, } \\
1823\end{array}$ & $\begin{array}{l}\text { Rio de } \\
\text { Janeiro: } \\
\text { Impressão } \\
\text { Régia, } 1811\end{array}$ & $\begin{array}{l}\text { Gazeta do } \\
\text { Rio de } \\
\text { Janeiro: 12/ } \\
10 / 1811 \\
\text { (loja da } \\
\text { Gazeta) }\end{array}$ & $\begin{array}{l}\text { Acervo } \\
\text { Pessoaal } \\
\text { José E. } \\
\text { Mindlin. } \\
\text { Cota: RBM } \\
\text { 8e (ed. } \\
1811 \text { ). } \\
\text { Biblioteca } \\
\text { Nacional de } \\
\text { Lisboa. } \\
\text { Cota: L } \\
8678 \text { P } \\
\text { (ed. 1823) }\end{array}$ \\
\hline $\begin{array}{l}\text { Perigos } \\
\text { Descobertos }\end{array}$ & & & & & $\begin{array}{l}\text { Diário do } \\
\text { Rio de } \\
\text { Janeiro: 08/ } \\
05 / 1822 \\
\text { (Paulo } \\
\text { Martin) }\end{array}$ & \\
\hline $\begin{array}{l}\text { Recreio } \\
\text { doméstico, } \\
\text { ou } \\
\text { ramalhete de } \\
\text { contos, } \\
\text { novellas, } \\
\text { historias, } \\
\text { ditos } \\
\text { galantes, } \\
\text { vidas de } \\
\text { grandes } \\
\text { homens }\end{array}$ & & & $\begin{array}{l}\text { Lisboa: } \\
\text { Imprensa de } \\
\text { Bernardo } \\
\text { José de } \\
\text { Alcobia, } \\
1815\end{array}$ & & $\begin{array}{l}\text { Gazeta do } \\
\text { Rio de } \\
\text { Janeiro: } 06 / \\
06 / 1816\end{array}$ & $\begin{array}{l}\text { Biblioteca } \\
\text { Nacional de } \\
\text { Lisboa. } \\
\text { Cota: L } \\
6590 \text { P } \\
\text { (ed. 1815) }\end{array}$ \\
\hline $\begin{array}{l}\text { Renato, } \\
\text { epizodio do } \\
\text { Gênio do } \\
\text { christianismo }\end{array}$ & $\begin{array}{l}\text { F. A. de } \\
\text { Chateaubriand } \\
\text { (Saint-Malo, } \\
\text { Brittany, } \\
1768- \\
\text { Paris, 1848) }\end{array}$ & $\begin{array}{l}\text { Bento Luís } \\
\text { Viana (São } \\
\text { Miguel, } \\
\text { ????-- } \\
\text { Paris, 1822) }\end{array}$ & & & $\begin{array}{l}\text { Diário do } \\
\text { Rio de } \\
\text { Janeiro: 04/ } \\
11 / 1821 \\
\text { (Manoel } \\
\text { Mandilo) }\end{array}$ & \\
\hline $\begin{array}{l}\text { Triste effeito } \\
\text { de huma } \\
\text { infidelidade }\end{array}$ & $\begin{array}{l}\text { Antoine } \\
\text { François } \\
\text { Prévost } \\
\text { (Hesdin, } \\
1697- \\
\text { Courteuil, } \\
1763 \text { ) }\end{array}$ & & $\begin{array}{l}\text { Lisboa: } \\
\text { Impressão } \\
\text { Régia, } 1818\end{array}$ & $\begin{array}{l}\text { Rio de } \\
\text { Janeiro: } \\
\text { Impressão } \\
\text { Régia, } 1815\end{array}$ & $\begin{array}{l}\text { Gazeta do } \\
\text { Rio de } \\
\text { Janeiro: } 24 / \\
01 / 1816 \\
\text { (loja da } \\
\text { Gazeta) }\end{array}$ & $\begin{array}{l}\text { Biblioteca } \\
\text { Nacional } \\
\text { do Rio de } \\
\text { Janeiro. } \\
\text { Cota: } 37 \text {, } \\
\text { 10, 11 (ed. } \\
\text { 1815). } \\
\text { Biblioteca } \\
\text { Nacional de } \\
\text { Lisboa. } \\
\text { Cota: L } \\
\text { 6602 P (ed. } \\
\text { 1818). }\end{array}$ \\
\hline
\end{tabular}

7 Fontes: CABRAL, Alfredo do. Annaes da Imprensa Nacional 1808-1822. Rio de Janeiro: Typographia Nacional, 1881 (reeditado no periódico: Cadernos do Centro de Pesquisas Literárias da PUCRS, Porto Alegre, v. 4 (3), 1998; CAMARGO, Ana Maria de Almeida e MORAES, Rubens Borba de. Bibliografia da Impressão Régia do Rio de Janeiro. São Paulo: EDUSP, Livraria Kosmos Editora, 1993. Pesquisa na base nacional de dados bibliograficos - PORBASE - disponível no site da Biblioteca Nacional de Lisboa <http://pesquisa.bn.pt>.

8 Fontes: Algumas informações foram retiradas a partir do frontispício das edições encontradas ou do termo bibliográfico, no caso das edições que foram enviadas pela Biblioteca Nacional de Lisboa; Também foram consultadas as obras de referência CABRAL, A., 1881. op. cit.; CAMARGO, A.; MORAES, R., 1993. op. cit.; OLIVEIRA, A., 1991. op. cit; SILVA, I., 1859. op. cit.; 
DEMOUGIN, J., 1994. op. cit; DRABBLE, M.; STRINGER, J., 1996. op. cit. Em alguns casos, foram consultados sites de biografias dos autores estrangeiros: <www.brainyhistory.com>; $<$ www.biografiasyvidas.com/biografia/r/restif.htm >; <http://www.arqnet.pt/dicionario/jacob.html $>$.

9 CABRAL, A., 1881. op. cit.; CAMARGO, A.; MORAES, R., 1993. op. cit.; SILVA, I., 1859. op. cit.; RODRIGES, A. Gonçalves. A tradução em Portugal. Lisboa: Imprensa Nacional, Casa da Moeda, 1992.

10 Gazeta do Rio de Janeiro (1808-1822). Microfilme. MEC - Biblioteca Nacional do Rio de Janeiro - Brasil - Serviço de Reprografia. (disponível no AEL - Arquivo Edgard Leuenroth/ Unicamp); Diário do Rio de Janeiro (1821-1822). Microfilme. MEC - SEAC plano nacional de microfilmagem de periódicos brasileiros - Fundação Casa de Rui Barbosa Rio de Janeiro. (disponível no AEL - Arquivo Edgard Leuenroth/Unicamp).

${ }_{11}$ Como os endereços nos anúncios referentes à loja da Gazeta e à livraria de Paulo Martin Filho coincidem, é possível deduzirmos de que o responsável pelas ofertas da loja da Gazeta fosse o livreiro Paulo Martin Filho.

12 Fonte manuscrita: Arquivo Nacional do Rio de Janeiro. Registro de Avisos e Oficios. Livro 7 da Corte -1814-1815 - IJJ 1 185. Série Interior Gabinete do Ministro. A6/Codes.

editoriais: alguns deles foram publicados em dois volumes, outros, em poucas páginas, como aponta o anúncio acima transcrito.

Em certo sentido, livros como esses últimos se assemelham aos da Bibliothèque Bleue, analisados por Roger Chartier. Os livros da Bibliothèque Bleue eram compostos com uma fórmula editorial de re-edição de textos já consagrados, escritos originalmente para um público intelectual e que, no processo de re-estruturação para que se tornassem mais acessíveis a um público de menores condições econômicas, obedeceram a certos requisitos, tais como a divisão do texto em parágrafos menores, a inserção de resumos e recapitulações, os cortes nos capítulos (principalmente das descrições) e a tentativa de simplificação das estruturas das orações. (CHARTIER, 1990).

Como acontece também com alguns dos romances da Impressão Régia do Rio de Janeiro, Chartier constatou que os livros franceses analisados foram impressos em tamanhos pequenos, in oitavo e in duodécimo, com número de páginas variado e que poucos eram os livros com imagens no corpo do texto, sendo que alguns apresentavam uma gravura na folha de rosto.

Quanto ao conteúdo dos romances, uma parte dos enredos trata de histórias em que os elementos do fantástico, do acaso e do exótico são utilizados freqüentemente. O gênero de literatura de viagens, por exemplo, foi apreciado pelo público de habitantes do Rio de Janeiro logo nos primeiros anos de atividade da Impressão Régia. Em voga desde o século XVI, e ainda detendo seu espaço no cenário literário europeu da segunda metade do século XVIII, as narrativas de viagens conquistaram o gosto popular com enredos de evasão que traziam aos europeus informações sobre os lugares longínquos, descrevendo os diferentes hábitos, práticas religiosas e de governo dos habitantes de distantes países, bem como suas paisagens exóticas. Entre as aventuras dos viajantes protagonistas, lidando com diferentes costumes e comparando com os que até então compreendiam como únicos, os autores do gênero muitas vezes inseriam um tom de crítica aos 
governos europeus ou à soberania de seus religiosos (MARTINS, 2004). Podemos citar como receptores setecentistas da tradição de narrativas de viagens, os romances Robinson Crosoe (1719), de Daniel Defoe, ou As viagens de Gulliver (1726) de Jonathan Swift (SERRA, 1997, p.18).

Em pelo menos um dos romances anunciados como publicações da Impressão Régia, A Choupana Índia, de 1811, é possível notarmos uma retomada às narrativas de viagens. Seu autor, Bernardin de Saint Pierre (17371814), se utiliza para isso das peripécias de um pesquisador que partiu para o oriente à procura de verdades existenciais sobre filosofia e religião que os parâmetros franceses não foram suficientes de revelar. Com base na investigação das diversas formas de vida e de culto das religiões dos diferentes lugares pelos quais passou, o viajante percebia que tão díspares reflexões não poderiam se concatenar numa única conclusão, que ele só encontrou na convivência com um selvagem. Isolado numa choupana afastada, em meio à natureza exuberante, sem que o convívio social pudesse corrompê-lo, este lhe explicou como vivia com tão poucos recursos e como venerava seu deus na natureza, sem intermediações de dogmas, rituais ou clérigos.

Os enredos escritos por penas femininas também circularam na Corte de D. João, como as Cartas de huma peruviana, romance de autoria da escritora francesa Françoise d'Issembourg d'Happoncourt de Graffigny, impresso na Impressão Régia de Lisboa em 1802 e anunciado no Rio de Janeiro por diferentes livreiros entre os anos de 1812 e 1815; e o romance de Mary Wortley Montagu, Carta escrita pela senhora, rezidente em Constantinopla, que foi anunciado na Gazeta do Rio de Janeiro em 1819. Tais publicações seguem uma tendência européia de composições femininas no gênero romance, que sobreviveu à perseguição da crítica dos romancistas seus contemporâneos e continuou fazendo sucesso no século XVIII. (VASCONCELOS, 2002, p. 103-104).

Os textos críticos ingleses do século XVIII estabeleceram uma diferenciação terminológica para os escritos em prosa de ficção produzidos antes de Pamela, 1740, e os posteriores Romance e novel passaram, então, a identificar, respectivamente, duas formas de escrita da narrativa ficcional que divergiam, basicamente, pela ausência ou presença do realismo e pelo modo com que este era tratado. Clara Reeve escreveu sobre essa diferenciação, considerando o novel como uma pintura do cotidiano, feita ao tempo da escrita, com uma narração verossímil, uma linguagem mais natural e mais próxima do leitor, o que, conseqüentemente, possibilitaria uma identificação com os personagens descritos:

O Romance [romanesco] é uma fábula heróica, que trata de pessoas e coisas fabulosas. - O Romance [moderno] é uma pintura dos costumes e da vida real do tempo em que foi escrito. O Romance [romanesco] descreve, em linguagem sublime e elevada, aquilo 
que nunca aconteceu nem poderia ter acontecido. - O Romance [moderno] faz uma narração familiar das coisas que acontecem todos os dias diante de nossos olhos, da forma como poderiam acontecer a um amigo nosso ou conosco mesmo; e sua perfeição está em representar cada cena de uma maneira tão fácil e natural, fazendo com que ela pareça tão provável, a ponto de nos enganar e persuadir (ao menos enquanto estamos lendo) de que tudo é real, até que sejamos afetados pelas alegrias e tristezas das pessoas da história, como se elas fossem nossas próprias. ${ }^{13}$

Podemos considerar como modernos ${ }^{14}$ uma parte dos romances que no período joanino circulavam no Rio de Janeiro, entre os quais figuram: Cartas Americanas, do português Theodoro José Biancardi (1777-18-), publicado em Lisboa no ano de 1809 e anunciado por diversas vezes entre 1810 e 1815; Paulo e Virgínia, do romancista francês Bernardin de Saint Pierre (1737-1814), saído dos prelos da Impressão Régia do Rio de Janeiro em 1811 e muito anunciado entre 1811 e 1815; e A Choupana Índia, do mesmo autor, dado à luz em 1806 pela tipografia portuguesa Rollandiana.

$\mathrm{O}$ autor de Cartas Americanas contextualiza seu enredo tanto histórico como geograficamente, descrevendo minuciosamente a cidade onde o protagonista se encontra. Já nos romances de Bernardin de Saint Pierre há um trabalho com a descrição dos personagens, atribuindo-lhes características físicas e psicológicas, além da localização espacial e da menção aos valores burgueses como a defesa da prática do trabalho em oposição ao ócio aristocrático.

Outro romance pode ser citado como exemplo de apropriação de valores burgueses, A filosofa por amor ou cartas de dois amantes apaixonados e virtuosos, do francês Rétif de la Bretonne (1734-1806), traduzida por Luís Caetano de Campos (1750-1820), publicada na Impressão Régia do Rio de Janeiro em 1811 e anunciada até 1815 . Seu enredo trata da individualidade,

ABREU, 2003. p. 292.

REEVE, Clara.The progress of romance. Colchester: W. Keymer, 1785. p. 111. Apud

${ }_{14}$ Características do romance moderno, tais como o relato de acontecimentos verossímeis, vividos por personagens que apresentam particularizações e, ainda, a identificação do leitor com os mesmos, foram aqui tratadas com base na análise de Ian Watt sobre romance inglês, que definiu as inovações no método narrativo da prosa ficcional como "realismo formal": "O método narrativo pelo qual o romance incorpora essa visão circunstancial da vida pode ser chamado seu realismo formal; formal porque aqui o termo 'realismo' não se refere a nenhuma doutrina ou propósito literário específico, mas apenas a um conjunto de procedimentos narrativos que se encontram tão comumente no romance e tão raramente em outro gêneros literários que podem ser considerados típicos dessa forma. Na verdade o realismo formal é a expressão narrativa de uma premissa que Defoe e Richardson aceitaram ao pé da letra, mas que está implícita no gênero romance de modo geral: a premissa, ou convenção básica, de que o romance constitui um relato completo e autêntico da experiência humana e, portanto, tem a obrigação de fornecer ao leitor detalhes da história como a individualidade dos agentes envolvidos, os particulares das épocas e locais de suas ações - detalhes que são apresentados através de um emprego da linguagem muito mais referencial do que é comum em outras formas literárias." (WATT, 1996, p. 27) 
uma vez que os personagens principais, pertencentes a classes sociais distintas, buscam realizar sua união mesmo que de encontro aos valores dos aristocráticos pais da amante, que ainda defendem os casamentos arranjados.

Outros romances publicados pela Impressão Régia do Rio de Janeiro apresentam ainda semelhanças com os que Bakhtin designa como "romance de aventuras de provações" ou "romance grego", nos quais um casal apaixonado passa por diversas provações até conseguir sua união no final do livro, auxiliados, quando necessário, por personagens ou riquezas providenciais. $O$ tempo no romance grego é identificado apenas pela seqüência de acontecimentos que não somos capazes de cronometrar, mesmo porque os personagens permanecem jovens e irresistivelmente belos até o fim, não sofrem mudanças físicas ou psicológicas com a passagem do tempo e as experiências vividas. Interferências do acaso, viagens por terras longínquas, além de encontros e desencontros sucessivos, incluindo o seqüestro da heroína e atentados contra a castidade da mesma, são tópicas constantes nesses romances. (BAKHTIN, 1993, p. 213-233).

Com base nos elementos dos enredos dos romances gregos, enumerados por Bakhtin, História de dois amantes ou o templo de Jatab, seria um texto típico. O romance de Henri François la Salle, traduzido por José Pedro de Souza Azevedo (17- -1812), impresso na Impressão Régia do Rio de Janeiro em 1811 e anunciado várias vezes entre 1811 e 1815, apresenta um casal de amantes jovens, cuja união não pode ser concretizada, que passa por inúmeros obstáculos até o fim do livro, sempre mantendo a jovialidade e conseguindo seu intento com auxílios e tesouros providenciais.

História de dois amantes, também foi tido como um romance de conteúdo lascivo. Antonio Candido cita essa obra, entre os comentários às publicações da Impressão Régia do Rio de Janeiro, adjetivando-a como "licenciosa" (CANDIDO, 1964, p. 231), atributo que indica a imagem que para a história dos amantes Zulima e Deley vem sendo construída desde o século XIX, pois Inocêncio Francisco da Silva, em 1859, assim já a qualificava:

É uma novella em que a modéstia e a honestidade dos costumes são mui pouco respeitadas. Não sei como em tempo de censura prévia se permitiu a sua impressão! E por mais de uma vez, pois vi d'ella segunda edição feita, se não me engano, em Rio de Janeiro. (SILVA, 1859, v. 7, p. 298).

Os conteúdos lascivos, encontraram espaço nos livros impressos no Rio de Janeiro, não obstante a censura que inspecionava os manuscritos e os pedidos de impressão e de circulação. Certamente, não traziam um conteúdo tão perigoso ou explicitamente obsceno como o dos livros analisados por Robert Darnton, que, examinando as listas de pedidos de livreiros 
franceses, em atividade entre as décadas de 70 e 80 do século XVIII, enviadas a Société Typographique de Neufchâtel, além das listas de livros apreendidos nas aduanas, verificou que os títulos recorrentes apontavam uma preferência pela literatura obscena, difamatória e sediciosa. Compunham o conjunto dessa literatura obras anticlericais, como Histoire de Dom B...; livros com enredos de orgias sexuais, como La putain errante; de cunho filosófico, como Questions sur l'Enciclopédie, de Voltaire; políticos, como Système social, de Holbach; biografias difamatórias, como $A$ Vie privée de Louis XV e as Chroniques Escandaleuses, como a de Guillaume Imbert Bourdeaux. (DARNTON, 1998, p. 87-91).

O título carioca $A$ filósofa por amor até poderia sugerir um enredo parecido com o do romance francês Teresa Filósofa (Thérèse philosophe ou Memoires pour servir à l'histoire du p. Dirrag et de Mlle Eradice) de JeanBaptististe de Boyer, publicado em 1748, em que Teresa, escondida dentro de um móvel ou atrás de arbustos, flagra relações sexuais de suas amigas e as descreve, de modo que o leitor também observe as cenas através do olhar da narradora. Mas a identificação entre as filósofas não passou do título, uma vez que a primeira, chamada Adelaida, em nada se aproxima da voyeur Teresa.

Porém, por mais que relativizemos o peso da moral, para os preceitos da religião e dos bons costumes da época, defendidos pelos órgãos da censura portuguesa, certamente seriam barrados romances escritos por autores já conhecidos na Europa por suas produções obscenas, como Rétif de la Bretonne, que na França publicou um tratado a favor da regulamentação da prostituição, em 1769, (Le Pornograohe ou ideés d'um honnête homme); e Antoine François Prévost (1753-1835), autor de Marquiz de Renoncour Histoire du Chevalier des Grieux et de manon Lescault, publicado em 1731, que teve uma versão impressa no Rio de Janeiro, pela Impressão Régia, no ano de 1815, com o título Triste effeito de huma infidelidade.

Ainda que os nomes dos autores fossem omitidos, certamente os enredos com relações sexuais ocorridas (e descritas) fora dos laços do matrimônio seriam proibidos. Além disso, há que se considerar que os régios liam a obra integralmente, antes de ditarem um parecer, como nos comprova a transcrição dos seguintes documentos, consultados por Márcia Abreu:

“EX ${ }^{\mathrm{mo}} \cdot \mathrm{R}^{\mathrm{mo}} . \mathrm{Snr}$ '

Por odem de V. Ex ${ }^{\mathrm{a}}$. $\mathrm{R}^{\mathrm{m}}$. li a Carta junta, escripta em Constantinopla, sobre as mulheres Turcas, seos modos de viver, $\mathbb{Q}^{\mathrm{a}}$. e nada achei de contrario a $\mathrm{S}^{\text {ta }}$. Fé, e bons costumes.

Este 'meo parecer; V. Exa. $\mathrm{R}^{\mathrm{ma}}$. Mandará o q'for servido.

Convento de S. Antonio do Rio de Janeiro 30 de outubro de 1819. Fr. Fran ${ }^{\text {co }}$. de S. Carlos."

"Senhor 
O Manuscrito junto intitulado - Carta escrita pela Senhora de... rezidente em Constantinopla $\&$. e que Zeferino Vito de Meireles pertender imprimir, nada contem contra o Estado, Fé ou Costumes, e por isso o julgo nas circunstancias de poder imprimir-se. Vossa Magestade Mandara o que fôr Servido. Rio de Janeiro, 22 de Novembro de 1819.

$D^{r}$. Fr. Joze Doutel

Censor Régio. (Arquivo Nacional do Rio de Janeiro: Mesa do Desembargo do Paço - Licenças. Caixa 821 (antiga 171). Pacote 04, doc 78)

Os exemplos de episódios picantes são variados: casais apaixonados que se entregam ao amor antes do casamento, pois para a cerimônia havia algum empecilho; uma noiva que resolve se amasiar com outro partido para fugir de um casamento arranjado; uma donzela desonrada por algum enganador que, a partir de então, se prostitui; vários maridos que traem suas esposas e as abandonam; sacerdotes que defloram súditas virgens inocentes; um soldado que engravida uma senhorita e a deixa para guerrilhar no Exército e até mesmo um general que estupra a filha de seu anfitrião. Exceção feita aos apaixonados apressados, que após poucas páginas conseguem realizar o casamento, e à prostituta que conta sua história num tom de advertência às donzelas, os personagens desses episódios não se arrependem de suas aventuras sexuais, embora, é preciso dizer, alguns sejam castigados pelo destino ou pelas esposas ultrajadas.

Juntamente com as obras publicadas pela Impressão Régia do Rio de Janeiro, figuravam nos anúncios de mercadores e livreiros muitos títulos vindos da Europa, principalmente de Lisboa. Apesar da censura nos portos e da demora em conseguir autorizações para importar e para vender os livros, podemos vislumbrar, sobretudo através dos anúncios nos periódicos, um certo número de profissionais que trabalhavam com o comércio de livros e, ainda, supor um público consumidor para os romances produzidos pela Impressão Régia do Rio de Janeiro ou trazidos do exterior.

Há, sem dúvida, uma heterogeneidade no conjunto de romances encontrados, tanto nos aspectos materiais quanto no conteúdo dos mesmos que apresentam enredos romanescos e de cavalaria (como em Lausus e Lydia e Metusko ou os Polacos) e temas modernos, bem localizados espaço-temporalmente, com críticas à sociedade e outras características dos romances realistas já consagrados. Isso sem falar dos contos moralizantes, cuja própria classificação no gênero apresenta dificuldades, dadas as suas curtas dimensões e a suposição de que tenham sido apenas adaptações de outros romances. E, ao que tudo indica, conviviam essas diferentes formas de apresentação material e a diversidade de conteúdos da prosa de ficção, comprovando que a circulação e o auge de um determinado gênero não necessariamente acarreta a detração de outros cuja leitura havia sido mais usual anteriormente. 


\title{
RESUMO
}

O que os leitores que viviam no Brasil no início do século XIX poderiam ler? Antes de 1808, poderiam apenas ler os livros importados da Europa, porém, com a inauguração da Impressão Régia, os luso-brasileiros puderam também adquirir livros impressos no Rio de Janeiro. Seguindo a tendência da importação de romances, em voga desde o século XVIII, os livreiros cariocas começaram a ofertar, nos jornais da época, romances produzidos na Impressão Régia. A partir do encontro e leitura desses romances, comentamos a materialidade com a qual eles foram impressos, com uma qualidade baixa, seus preços e o fato de terem sofrido alterações editoriais. Esses aspectos podem apontar um tipo de público e ainda influenciar diferentes processos de compreensão. Além disso, adentrando os textos, procuramos entender que tipos de narrativas são apresentadas. Entre os assuntos abordados nas publicações da Impressão Régia, consideramos aqui romances, narrativas de viagens e contos (i)morais.

Palavras-chave: Prosa de ficção; história editorial; século XIX.

\begin{abstract}
What kind of reading material did the Brazilian have available in the beginning of the $19^{\text {th }}$ century? Before 1808 , only imported books from Europe, but with the inauguration of the Impressão Régia, people could also acquire books printed in Rio de Janeiro. Following the trend of importing novels, established since the $18^{\text {th }}$ century, Rio's booksellers started offering, through local newspapers, novels published by the Impressão Régia. Once such novels were found and read, we comment on how these books were poorly printed, on their prices and on the fact that they were altered by the editor. These aspects may indicate a specific public and influence on different comprehension processes. Furthermore, by screening the texts, we try to understand what kinds of narratives are presented. Among the subjects commonly treated by The Impressão Régia's publications, we here have a take on the novels, traveling narratives and (I)mmoral tales.
\end{abstract}

Key-words: Fiction narratives; editorial history; eighteenth century. 
SOUZA, S. C. M. de. Primeiras impressões: produção e circulação de romances...

\section{REFERÊNCIAS}

ABREU, Márcia Azevedo de. Os caminhos dos Livros. Campinas. SP: Mercado de Letras, Associação de Leitura do Brasil (ALB); São Paulo: Fapesp, 2003.

BAKHTIN, Mikhail. Questões de literatura e de estética. São Paulo: Hucitec, 1975.

CABRAL, Alfredo do Valle. Annaes da Imprensa Nacional do Rio de Janeiro 1808 a 1822, Typographia Nacional, 1881.

CAMARGO, Ana Maria de Almeida; MORAES, Rubens Borba de. Bibliografia da Impressão Régia do Rio de Janeiro. São Paulo: Edusp, Livraria Kosmos Editora, 1993, 2 v.

CANDIDO, Antonio. Formação da literatura brasileira. São Paulo: Martins Fontes, 1964.

. A educação pela noite e outros ensaios. São Paulo: Ática, 2003.

CASANOVA, Pascale. A república mundial das letras.Tradução: Marina Appenzeller. São Paulo: Estação Liberdade, 2002.

CHARTIER, Roger. A História Cultural entre práticas e representações. Rio de Janeiro: Bertrand do Brasil. 1990.

COSTA, Hipólito José da. Correio Braziliense, ou Armazén Literário. Hipólito José da Costa. São Paulo: Imprensa Oficial do Estado: Brasília: Correio Braziliense, 2002.

DARNTON, Robert. Os Best-sellers priobidos da França pré-revolucionária. Tradução: Hildegard Feist. São Paulo: Companhia das Letras, 1998.

GOULEMOT, Jean-Marie. Esses livros que se lêem com uma só mão: leitura e leitores de livros pornográficos no século XVIII. Tradução: Maria Aparecida Corrêa. São Paulo: Discurso Editorial, 2000.

HALLEWELL, Laurence. O Livro no Brasil. Tradução: Maria da Penha Villalobos e Lolio Lourenço de Oliveira. São Paulo: T. A. Queiroz, Edusp, 1985. Original inglês.

MARTINS, João Paulo. História e romance: a idéia de história em Aventuras de Telêmaco e as relações entre o texto histórico e a prosa ficcional na passagem dos séculos XVII-XVIII. In: SEMINÁRIO BRASILEIRO SOBRE O LIVRO E A HISTÓRIA EDITORIAL [COMUNICAÇÃO], 1., 8-12 nov. 2004. Disponível em: <http://www.livroehistoriaeditorial.pro.br/pdf/ joaopaulommartins.pdf > Acesso em: 20 dez. 2004.

RODRIGUES, A. Gonçalves. A tradução em Portugal. Lisboa: Imprensa Nacional. Casa da Moeda, 1992.

SERRA, Tania Rebelo Costa. Antologia do romance-folhetim (1839-1870). Brasília: Universidade de Brasília, 1997.

SILVA, Inocêncio Francisco da. Diccionário Bibliográfico Portuguez: estudos de Innocencio Francisco da Silva aplicáveis a Portugal e Brasil. Lisboa: [s.n.], 1859.

SILVA, Maria Beatriz Nizza da. Cultura e sociedade no Rio de Janeiro (1808-1821). São Paulo: Com. Ed. Nacional, 1977.

VASCONCELOS, Sandra Guardini T. Dez lições sobre o romance inglês do século XVIII. São Paulo: Boitempo, 2002.

. Formação do romance brasileiro: 1808-1860. Vertentes inglesas. Disponível em: <http:/ /www.unicamp.br/iel/memoria/Ensaios/index.htm> Acesso em: 25 jan. 2005.

WATT, Ian. A ascensão do romance. São Paulo: Companhia das Letras, 1990.

Periódicos:

Gazeta do Rio de Janeiro (1808-1822). Microfilme. MEC - Biblioteca Nacional do Rio de Janeiro - Brasil - Serviço de Reprografia. (disponível no AEL - Arquivo Edgard Leuenroth/Unicamp).

Diário do Rio de Janeiro (1821-1822). Microfilme. MEC - SEAC plano nacional de microfilmagem de periódicos brasileiros - Fundação Casa de Rui Barbosa Rio de Janeiro. (disponível no AEL Arquivo Edgard Leuenroth/Unicamp). 